\title{
Insight
}

\section{Bioenergy Sustainability at the Regional Scale}

\author{
$\underline{\text { Virginia H. Dale }}^{1}, \underline{\text { Richard Lowrance }}^{2}$, Patrick Mulholland $^{3}{ }^{\text {, and } \underline{\text { G Phillip Robertson }}^{4}}$
}

\begin{abstract}
The establishment of bioenergy crops will affect ecological processes and their interactions and thus has an influence on ecosystem services provided by the lands on which these crops are grown. The regional-scale effects of bioenergy choices on ecosystem services need special attention because they often have been neglected yet can affect the ecological, social, and economic aspects of sustainability. A regional-scale perspective provides the opportunity to maximize ecosystem services, particularly with regard to water quality and quantity issues, and also to consider other aspects of ecological, social, and economic sustainability. We give special attention to cellulosic feedstocks because of the opportunities they provide.
\end{abstract}

Key Words: bioenergy crops; ecosystem services; landscape; management

\section{INTRODUCTION}

The expansion of biomass production to provide feedstocks for biofuel refineries will induce complex interactions among a large number of ecological processes that are important but, as yet, poorly understood. Currently, most liquid biofuels use sugar, grain, and vegetable oils as feedstocks. However, there is great potential to expand feedstocks to herbaceous and woody lignocellulosic crops and agricultural and forest wastes in particular (NRC 2009). Bioenergy crop expansion will influence local and regional sustainability via impacts to socioeconomic systems and will also change the delivery of ecosystem services provided by current landscapes (Robertson et al. 2008). Many of these alterations could be positive if managed appropriately (Kline et al. 2009). They include effects on water quality and quantity, soil conditions, greenhouse gas emissions, air quality, and biodiversity.

The shift from a pre-existing crop or from a relatively unmanaged ecosystem to a bioenergy crop will be accompanied by changes in land management that will include altered fertilization, irrigation, cultivation, and harvesting regimes. These changes will affect a number of ecosystem components and the magnitude and efficiency of the ecological services they provide. Changes in soil composition and structure, for example, will affect nutrient cycling, runoff characteristics, soil erosion, downstream surface waters and aquifers, and greenhouse gas emissions. Where the transition is to a perennial cellulosic crop, biogeochemical changes are likely to be positive as carbon is sequestered belowground, greenhouse gas emissions are abated, and less nitrate and phosphorus is delivered to surface and ground waters (Robertson et al. 2011). Hydrologic changes are also likely as altered water demands influence the availability of water for other potential uses, and biodiversity changes will affect the delivery of ecosystem services, such as pest suppression in surrounding ecosystems (Landis et al. 2008, Gardiner et al. 2010). Of course, changes due to bioenergy need to be compared to the environmental effects of using other energy sources such as petroleum, including exploration, drilling, production, transport, and use, but many of these effects are poorly documented (Ramseur 2010).

These aspects of ecological systems are complex, and how they interact can vary widely from one ecosystem to another. Different components, individually or in combination, provide a suite of ecological services such as water and air purification, the provision of wildlife habitat, 
biodiversity maintenance, waste decomposition, pollination of crops and other plants, seed dispersal, groundwater recharge, greenhouse gas and climate regulation, food, fiber, and fuel production, and aesthetics and cultural amenities (Millennium Ecosystem Assessment 2005, Swinton et al. 2007). Many effects of traditional agriculture on ecosystem services are known (e.g., Dale and Polasky 2007, NRC 2010), yet only recently have researchers begun to explore how bioenergy crops, and specifically cellulosic feedstocks, will affect these services (Hecht et al. 2009). The assessment of where bioenergy crops can best be grown and how they can influence ecosystem services on a regional scale requires integrated consideration of both typical agriculture and land not traditionally used for crops.

An example of a process that interacts with several others and that can be considered at many scales is the fate and transport of carbon and nitrogen during biomass production. The carbon and nitrogen cycles are driven by factors such as precipitation, temperature, topography, soil characteristics, the presence and activities of soil microbes and invertebrates, and land management. Changes to any of these factors can have significant effects on biofuel crop growth and on local carbon and nitrogen cycles. These local changes, when implemented across millions of hectares, will either: mitigate or exacerbate atmospheric greenhouse gas concentrations, for example; abate or accelerate nitrate contributions to eutrophication of inland waters and the extent of coastal dead zones; or increase or lessen sediment loads to streams and reservoirs. A corollary is that carbon and nitrogen cycles also vary depending on the type of feedstock planted and management practices.

Our perspective of bioenergy sustainability at a regional scale is built upon the concept that lands should be used for their most appropriate purpose and management decisions made in hierarchical fashion (Dale et al.2011). This premise derives from Forman's (1995) suggestion that, under ideal circumstances, land decisions occur hierarchically: first, addressing water and biodiversity concerns; second, food cultivation, grazing, and wood products; third, sewage and other wastes; and fourth, homes and industry. In this paradigm, decisions about energy use and other natural resource extractions would likely fall into a secondary tier under the second category. That is, after decisions are made about the locations for natural resource protection and about food and fiber, then decisions are made about fuel. As such, energy crops might be placed best on lands of marginal use for other purposes, including land less appropriate for growing food.

Landscape-level decision making is relatively rare, but access to science-based scenario forecasting can provide regional stakeholders and policy makers an opportunity to envision the long term outcomes of contemporary land use decisions (e.g., Baker et al. 2004), and thereby an opportunity to shape policy to enhance the delivery of ecosystem services in future landscapes. Of course, for science to influence decision making processes, it needs to be clear who makes decisions and how permanent and far reaching those decisions are. That is a topic that is beyond the focus of this paper, but one that needs to be addressed for bioenergy sustainability to be achieved.

Growing crops for bioenergy offers an opportunity to rethink, from a regional perspective, how and where feedstocks can sustainably be produced. The debated concepts on indirect land use effects (Mathews and Tan 2009) cause us to consider how even unmanaged ecosystems are influenced by human activity. The concept of "emerging ecosystems" recognizes that the majority of the Earth is affected by human activities with broadscale effects poorly understood (Hobbs et al. 2006, 2009). The properties of these novel systems may not be the same as the characteristics of natural ecosystems that ecologists have long studied. Although there is a rich literature on old-field succession, recovering wetlands, and some other managed systems, growing bioenergy feedstocks will involve lignocellulosic crops and management practices for which there is relatively little information or experience. Furthermore, the focus on sustainability provides an opportunity to decide how biofuels might be "done right" (Kline et al. 2009) and thus to provide a positive example for other cropping systems. The principles and processes of these human-managed, emerging ecosystems need to be better understood, especially in view of the regional landscape, which may contain a mix of agriculture, forest, urban, and other land uses. This lack of insight makes it difficult to develop land management goals for such ecosystems. Production of bioenergy crops and even use of residues of traditional crops for biofuels may produce many such emerging ecosystems, and research on the regional implications of those 
emerging ecosystems will be required to extend current ecological knowledge to these new situations.

\section{INFORMATION NEEDS FOR REGIONAL PERSPECTIVE}

In a regional context, it is important to consider ecological, societal, and economic issues and to address the trade-offs among those issues, including the potential unintended consequences. For example, the $19 \%$ increase in corn acreage in the $U$. S. from 2006 to 2007 reduced crop diversity and appears to have reduced biological pest control services by as much as $24 \%$ with an estimated cost of $\$ 58$ million $\mathrm{y}^{-1}$ in reduced yield and increased pesticide use for Iowa, Michigan, Minnesota, and Wisconsin (Landis et al. 2008). By contrast, if more perennial grasses are grown in a region, it is not now clear how such a change in landscape diversity might affect insect populations. Science must provide information about such consequences before inappropriate conclusions are drawn and policies set.

Research also needs to address both short and long term perspectives. For example, longer term goals need to be considered in order to grow crops in an ecological as well as socioeconomic context. Over time, the knowledge base about these bioenergy crops will grow, and management practices can adjust to improve ecological, social, and economic well-being. To build this knowledge, planting and management regimes can be treated as experiments under which data can be collected to build or refute our current understanding of how ecosystem services are affected by certain practices. In other words, treating bioenergy cropping systems under an adaptive management approach (Gunderson 2000) fosters learning about appropriate ways to manage these systems at the same time that bioenergy cropping is expanding. In particular, it is important to document ways in which these bioenergy cropping systems can be resilient in the face of changes in climate, biodiversity, and management practices and still provide key ecosystem services (Folke et al. 2004).

\section{SCIENCE NEEDED FOR BIOFUEL SYSTEMS TO FACILITATE DECISION MAKING AT DIFFERENT SCALES}

To influence biofuel management practices, science needs to be integrated into decision making processes before decisions are formed and implemented. To influence decisions about bioenergy crops and their management, models need to be constructed and tested so that they reflect the fact that all potential biofuel crops have costs and benefits with respect to socioeconomic systems as well as ecosystem services. The regional-ecology approach should take into consideration possible competition with current social and economic activities, organizations, methods of production, and infrastructures that serve the population of the region and that help provide livelihoods. For example, such an approach should consider not only land management activities and how they might affect ecological systems but also how farmers might be able to use the equipment, seeds, processing plants, and labor pool they already have.

A series of independent regional studies will help foster development of understanding about general ecological, societal, and economic principles and processes, particularly how, when, and where they operate across regions. Because these ecological, societal, and economic processes will differ across regions, the details of implementing biofuel production and the trade-offs that will need to be made will also vary from region to region. In many cases, science will be able to provide information to identify trade-offs and to guide decisions. There will be some places where biofuel crops can be grown sustainably and some where they cannot. In many cases, such judgments about crop sustainability will need to be made not for entire regions but for fractions of the landscape. These areas and the percentages of suitable land for biofuel-feedstock production will differ by region and will be determined by landscape quality, current and past land use, and socioeconomic capacities of the region.

Opportunities for research exist at this regional scale, which is less understood than either smaller or larger scales. The components of the regionalscale ecosystem, i.e., water, nutrients, vegetation, air, biodiversity, landforms, and soil, as well as their interactions are important to study and model. This research will provide several benefits. It will help to prioritize the individual components and develop 
ways to investigate their actions. It will lead to new ways to measure the components' salient characteristics. It will also allow scientists to study the interactions among the components so that the entire system can be understood. The research process should lead to ways to determine when sufficient understanding of the ecosystem exists to allow confidence in a resulting model's ability to predict the reaction of a region to changes that exceed the conditions for which data have already been collected. Finally, the scientific investigations should identify several disparate regional-sized units in which comparisons can help formulate a fundamental understanding of landscape processes and conditions.

\section{A CASE STUDY: REGIONAL WATER ISSUES}

An example of the research opportunities existing in the regional ecology of biofuel production is offered by a consideration of the more limited component of water quality, demand, and supply for biofuel production in the U.S. Assessing how an expansion of biomass and biofuel production will affect water quality, demand, and supply in a specific area depends on a wide range of issues that will vary considerably by region. These issues include existing pressures on water supply, biomass feedstock type and management, the types of lands devoted to biomass production, precipitation patterns and climate change, and technical methods used to convert biomass to biofuels. The overarching consideration that integrates all these issues is what type of ecosystems will be displaced by biomass production systems and whether the water quality and quantity effects of these conversions be negative, positive, or some combination of both. Increased areas of crops that are unable to retain soil and nutrients and that require irrigation or high fertilizer applications could threaten water quality and supply. The synchrony between plant available nitrogen and crop demand is a critical part of the plant-soil environment (e.g., Cassman et al. 2002).

Biofuels based on cellulosic feedstocks such as woody vegetation, e.g., intensive, short-rotation forestry, or perennial grasses, e.g., switchgrass, have the potential to reduce storm runoff, soil erosion by water runoff, and nutrient and pesticide exports to surface and ground waters in agricultural areas. However, most studies of cellulosic feedstocks have limited their focus to optimizing growth conditions and output, and relatively few have examined the impacts of biomass production on water quality and availability. This lack of data limits our ability to make reliable assessments about future water impacts for different cellulosic feedstocks suited to the different growing conditions around the country.

\section{Land management and water quality}

Application of fertilizers, pesticides, and other agrochemicals has become a standard practice for the production of both annual and perennial crops, but the needed amount of these inputs varies greatly by crop type and location. Nutrient runoff from fertilized crops within river basins has been one of the factors contributing to oxygen-deprived "dead zones" that threaten marine life, e.g., in such places as the Gulf of Mexico (Diaz and Rosenberg 2008). Studies conducted only at fine scales of plots or fields are not able to capture how sedimentation and nitrogen and phosphorus concentration at multiple scales are influenced by various cropping practices (Robertson et al. 2007). Yet at the scale of large watersheds, e.g., the Mississippi River watershed, farm practices have environmental effects, such as on the size and extent of the Gulf of Mexico hypoxic zone (Donner and Kucharik 2008, Dale et al. 2010). The pattern, type, and management of bioenergy crops can affect coastal eutrophication, either negatively, if crops that require large amounts of fertilizer are expanded, or positively, if bioenergy crops that need little fertilizer are planted in large areas or as stream buffers (Dale et al. 2010). Modeling and field experiments at intermediate and large scales are needed to characterize the landscape design for planting and management that would reduce hypoxia conditions and benefit other ecosystem services. This is a scale-dependent issue because the amount of nutrient and sediment transported to the Gulf is not simply a direct function of what is coming off the field but must also include what's lost along the way as water moves through the drainage network (Alexander et al. 2000).

Soil erosion that moves sediments and sedimentbound nutrients and pesticides into waterways is another factor influencing water quality. About half of the sediment deposited in U.S. surface waters is estimated to come from cropland erosion (Terrell and Perfetti 1993). Management practices used on croplands largely determine the extent of erosion. 
For example, more intensive agricultural practices, such as tillage of row crops, over-harvesting of corn stover and other cellulosic residues, or annual crop production on erodible marginal lands, can cause erosion and sediment deposition in waterways. Conservation practices with cover crops, vegetative filter strips, and riparian buffers can substantially reduce nutrient and sediment export in agricultural catchments (Dillaha et al. 1989, Rasse et al. 2000, Kaspar et al. 2007), and changes to local catchments in which the management occurs can accumulate into changes for entire watersheds, even for areas as large as the $48 \%$ of the U.S. that drains into the Gulf of Mexico.

Several studies have used the Soil and Water Assessment Tool (SWAT) watershed-scale model to predict water quality changes resulting from conversion of corn or other annual crops to switchgrass in the U.S. Midwest (e.g., Nelson et al. 2006, Vadas et al. 2008). The SWAT model relies on input from an economic model to identify specific agricultural lands for conversion to switchgrass on the basis of growth conditions and an assumed crop price. Modeling studies for Iowa, Kansas, and the upper Mississippi River valley suggest that 17 to $43 \%$ of current cropland could potentially be converted to switchgrass, resulting in erosion rate reductions from $20 \%$ to more than $90 \%$ and nitrogen- and phosphorus-export reductions of up to $60 \%$ if fertilizers are not used. However, nitrogen and phosphorus export from switchgrass fields is highly dependent on how fertilizer is applied. Future research should focus on land use designs, site preparation, use of cover crops, and fertilizer and pesticide management approaches that minimize surface runoff, erosion, and the export of sediments, nutrients, and pesticides from biofuel feedstock crops. To reduce or eliminate the need for fertilizer inputs in bioenergy crops, future research should also include understanding molecular mechanisms underlying plant-root, fungal, and microbial-community symbioses that enhance plant-nutrient availability. Finally, there are very few watershed-scale field studies that provide realworld data that can be used to validate the model results showing water quality benefits of conversion to cellulosic bioenergy crops, and such studies are urgently needed.

Despite a long history of forestry research, few studies have examined the water quality impacts of intensive, short-rotation silviculture for bioenergy production. Conversion of unmanaged forests to biomass production for biofuels could produce negative effects, depending on where those lands are located and how they are managed. An East Texas study of intensive-forestry impacts indicated significant increases in storm runoff, erosion, and nutrient loss relative to reference sites, but the impacts were highly variable over time because of the influences of the harvest cycle and weather and varied with management practices such as site preparation, burning, fertilization, and harvesting (McBroom et al. 2008a, 2008b).

\section{Water demand and supply}

In the U.S., agriculture is the second largest consumer of water from aquifers and surface supplies, i.e., blue water, and is the major industry using water stored in soil and transpired by plants, i.e., green water (Falkenmark and Rockstrom 2006). The future biofuel production industry will create new demands on the quantity of water used by agriculture and production forestry. Globally, commercial bioenergy production is projected to consume 18 to $46 \%$ of the current agricultural use of water by the year 2050 (Berndes 2002). New tools are needed to account for these demands and to guide management strategies as the nation implements sustainable biofuel production. Water requirements for processing biomass into biofuel are also important, but the quantity of water consumed by processing facilities is considerably less than that consumed by crop cultivation, and the efficiency of water use in biorefineries continues to increase (Robertson et al. 2007, Wu et al. 2009).

In many parts of the U.S., the agricultural sector already faces water shortages. In the arid west, agricultural withdrawals account for 65 to $85 \%$ of total water withdrawals (Wiebe and Gollehon 2006). In the east, supplies are under pressure from competing uses, especially in periods of drought. Although overall water use in the U.S. decreased in 1985 and has remained steady since then (Wiebe and Gollehon 2006), efficiency improvements are still possible in irrigation and other use sectors.

The amount of both green and blue water needed for a biofuel-based energy supply is greater than that used historically by the fossil-fuel-based economy. For instance, the consumptive water use in corn based bioethanol is about 4 gallons of water per gallon of ethanol compared with consumptive water use of about 1.5 gallons/gallon for typical petroleum 
refining (Pate et al. 2007). Other biorefinery technologies have various consumptive uses (volume water /volume fuel) of water. Current estimates for cellulosic conversion to ethanol and for thermochemical conversion range from two to six gallons/gallon (Pate et al. 2007). These figures do not include either green or blue water used for feedstock production or blue water used for petroleum extraction. Blue water use can range from zero for feedstocks grown without irrigation to very high values, such as the estimate of $780 \mathrm{~L} / \mathrm{L}$ for irrigated corn grown in Nebraska (NRC 2008).

The data needed to assess future impacts of cellulosic feedstock production on the water supply will require investigation of mixed agricultural systems that vary by location and could be difficult to monitor. Although some water inputs from rainfall or irrigation are incorporated into crop biomass, most are lost through evapotranspiration (ET, soil evaporation and plant transpiration), runoff to surface waters, or infiltration of ground water. ET rates vary by crop, and perennial bioenergy crops, both woody and herbaceous, have shown higher ET and less infiltration than have annual crops or natural ecosystems (Rowe et al. 2009, Robertson et al. 2011). One concern is a reduction in stream baseflows with conversion of agricultural lands, particularly pasture and other low-intensity agriculture, to perennial bioenergy crops. However, modeling for ET and water use of different crops, which has largely been limited to the field scale, has shown that expansion of perennial crops did not decrease water flow to streams, rivers, lakes, and groundwater. A SWAT modeling study in Minnesota (Folle and Mulla 2009) showed only a $0.35 \%$ decrease in streamflow when $27 \%$ of the watershed was converted to switchgrass instead of conventional crops. Methods for linking data from the field scale to the watershed level are needed to validate these modeled results.

Analysis of benefits and costs of future bioenergy feedstock production will better represent water resource trade-offs when carried out on a watershed basis. Combining life cycle analyses and environmental-cost accounting with watershed hydrologic and water-quality modeling will provide appropriate tools for the analysis of the water requirements of biofuel conversion plants and their needed feedstock supplies.

Research is under way at the watershed-scale level to develop the methods needed (Steiner et al. 2008) to understand the implications of future biofuel production on systems and make science-based decisions that will lead to greater sustainability. Also, results of forest conversion experiments from long term monitoring catchments, e.g., gauged catchments on experimental forest within the U.S. Forest Service, are providing historical data that can be used for improved models. Research is needed to expand methods and information systems to extend evapotranspiration, runoff, and infiltration models from watershed scales to greater regional scales across the entire country. Furthermore, the combination of life cycle analysis and environmental cost accounting with watershed hydrological and water-quality modeling will provide improved tools for analyzing the water requirements of feedstock supplies as well as biofuel conversion plants. A critical research need is to examine how the expansion of biofuels and more intensive agriculture will affect the water cycle and future precipitation patterns, especially within the context of the uncertainty in future climate change.

\section{RESEARCH OPPORTUNITIES}

Within this regional framework of scientific inquiry, four pressing research needs can be identified.

1. Understanding the data and knowledge requirements for quantitative modeling is necessary to improve projections of different land management practices on the delivery of ecosystem services. This effort will require adaptation or development of models that reflect the effects of converting agricultural crops, forests, and other land uses to bioenergy feedstock production under a variety of management conditions. The model projections must be validated with data obtained from watershed-scale field studies. Developing such an understanding will also enable determining the influence of future climate change scenarios on hydrology and bioenergy production and the potential impact of landscape alteration due to fuel crop conversion on local precipitation and other weather variables.

2. Understanding the impact of biofuel production on the many aspects of sustainability will improve via adaptive 
management. It will require field trials that generate near real time data for identifying the impact of bioenergy crop production on environmental parameters and expansion of models to include these new data. Furthermore, linking watershed-scale field research and modeling of water quantity and quality with information on soil processes, crop growth, and biodiversity fosters more accurate projections of the effects of biomass management options.

3. Improvements are needed in approaches to bioenergy feedstock management at a regional scale. New approaches need to be developed for agricultural and silvicultural land use design and management practices that reduce runoff of sediments, nutrients, pesticides, or other inputs; that minimize the greenhouse gas emissions from current and future cropping systems; and that enhance the delivery of biodiversity services such as pollination and biological pest control. Integrated decision making tools at farm, regional, watershed, state, and national levels can be developed by integrating data from appropriate spatial and temporal scales of water use, supply, and quality. Strategies for site preparation, management, and harvesting for bioenergy crops and forestlands can be developed to protect and improve water quality; to mitigate greenhouse gas concentrations in the atmosphere; and to enhance other services provided by agricultural landscapes.

4. Landscape ecology approaches at regional scales need to be applied in order to develop an understanding of relationships among diverse processes. Analytical frameworks can be designed for regional-scale ecological models. These models can then be linked with biophysical and economic models to understand how key aspects of bioenergy production affect the multifunctional roles of agricultural and forest landscapes. Finally, regional models can also enable the evaluation of management options for climate change scenarios.

Conducting broad-scale research requires both a plan and a focus on regional effects of bioenergy decisions. Critical thinking should be carried out for all the other components of the regional-scale ecology of biofuel production and consider sustainability from cradle to grave of the fuel cycle as compared to effects of using other sources of energy. Biofuel-production research directions and agendas should be developed for those other components, as is discussed here for U.S. water quality, demand, and supply. It is only with the full system perspective at appropriate scales for considering effects and decision making that sustainability of the bioenergy system can be addressed.

Responses to this article can be read online at: http://www.ecologyandsociety.org/voll5/iss4/art23/ responses/

\section{Acknowledgments:}

This research was supported by the U.S. Department of Energy (DOE) under the Office of the Biomass Program. Partial support was also provided by DOE Great Lakes Bioenergy Research Center and the Michigan Agricultural Experiment Station. Allen McBride and Peter Schweizer provided useful comments on an earlier version of the manuscript. We appreciate the assistance of Frederick O'Hara in editing the manuscript and Lindsey Amason in organizing the references. Oak Ridge National Laboratory is managed by the UT-Battelle, LLC, for DOE under contract DE-AC05-00OR22725.

\section{LITERATURE CITED}

Alexander, R. B., R.A. Smith, and G. E. Schwarz. 2000. Effect of stream channel size on the delivery of nitrogen to the Gulf of Mexico. Nature 403:758-761.

Baker, J., D. Hulse, S. Gregory, D. White, J. Van Sickle, P. Berger, D. Dole, and N. Schumaker. 2004. Alternative futures for the Willamette River basin, Oregon. Ecological Applications 14:313-324.

Berndes, G. 2002. Bioenergy and water - the implications of large-scale bioenergy production for water use and supply. Global Environmental Change-Human and Policy Dimensions 12:253-271. 
Cassman, K. G., A. Dobermann, and D. T. Walters. 2002. Agroecosystems, nitrogen-use efficiency, and nitrogen management. Ambio 31:132-140.

Dale, V. H., and S. Polasky. 2007. Measures of the effects of agricultural practices on ecosystem services. Ecological Economics 64:286-296.

Dale, V. H., C. Kling, J. L. Meyer, J. Sanders, H. Stallworth, T. Armitage, D. Wangsness, T. S. Bianchi, A. Blumberg, W. Boynton, D. J. Conley, W. Crumpton, M. B. David, D. Gilbert, R. W. Howarth, R. Lowrance, K. Mankin, J. Opaluch, H. Paerl, K. Reckhow, A. N. Sharpley, T. W. Simpson, C. Snyder, and D. Wright. 2010. Hypoxia in the Northern Gulf of Mexico. Springer, New York, New York, USA.

Dale, V. H, L. Wright, K. L. Kline, R. Perlack, R. L. Graham, M. Downing. 2011. Interactions between bioenergy feedstock choices and landscape dynamics and land use. Ecological Applications, in press.

Diaz, R. J., and R. Rosenberg. 2008. Spreading dead zones and consequences for marine ecosystems. Science 321:926-929.

Dillaha, T. A., J. H. Sherrard, and D. Lee. 1989. Long-term effectiveness of vegetative filter strips. Water, Environment and Technology 1:419-421.

Donner, S. D., and C. J. Kucharik. 2008. Cornbased ethanol production compromises goal of reducing nitrogen export by the Mississippi River. Proceedings of the National Academy of Sciences of the United States of America 105:4513-4518.

Falkenmark, M., and J. Rockstrom. 2006. The new blue and green water paradigm: breaking new ground for water resources planning and management. Journal of Water Resources Planning and Management-Asce 132:129-132.

Folke, C., S. Carpenter, B. Walker, M. Scheffer, T. Elmqvist, L. Gunderson, and C. S. Holling. 2004. Regime shifts, resilience, and biodiversity in ecosystem management. Annual Review of Ecology Evolution and Systematics 35:557-581.

Folle, S., and D. Mulla. 2009. Modeling upland and channel sources of sediment in the Le Sueur River watershed, Minnesota. Proceedings of the 5th
International SWAT Conference. Boulder, Colorado, USA.

Forman, R. T. T. 1995. Land mosaics: the ecology of landscapes and regions. Cambridge University Press, Cambridge, UK.

Gardiner, M. A., J. K. Tuell, R. Isaacs, J. Gibbs, J. S. Ascher, and D. A. Landis. 2010. Implications of three biofuel crops for beneficial arthropods in agricultural landscapes. Bioenergy Research 3:6-19.

Gunderson, L. H. 2000. Ecological resilience - in theory and application. Annual Review of Ecology and Systematics 31:425-439.

Hecht, A. D., D. Shaw, R. Bruins, V. Dale, K. Kline, and A. Chen. 2009. Good policy follows good science: using criteria and indicators for assessing sustainable biofuels production. Ecotoxicology 18:1-4.

Hobbs, R. J., S. Arico, J. Aronson, J. S. Baron, P. Bridgewater, V. A. Cramer, P. R. Epstein, J. J. Ewel, C. A. Klink, A. E. Lugo, D. Norton, D. Ojima, D. M. Richardson, E. W. Sanderson, F. Valladares, M. Vila, R. Zamora, and M. Zobel. 2006. Novel ecosystems: theoretical and management aspects of the new ecological world order. Global Ecology and Biogeography 15:1-7.

Hobbs, R. J., E. Higgs, and J. A. Harris. 2009. Novel ecosystems: implications for conservation and restoration. Trends in Ecology \& Evolution 24 :599-605.

Kaspar, T. C., D. B. Jaynes, T. B. Parkin, and T. B. Moorman. 2007. Rye cover crop and garnagrass strip effects on NO3 concentration and load in tile drainage. Journal of Environmental Quality 36:1503-1511.

Kline, K., V. H. Dale, R. Lee, and P. Leiby. 2009. In defense of biofuels, done right. Issues in Science and Technology 25:75-84.

Landis, D. A., M. M. Gardiner, W. van der Werf, and S. M. Swinton. 2008. Increasing corn for biofuel production reduces biocontrol services in agricultural landscapes. Proceedings of the National Academy of Sciences of the United States of America 105:20552-20557. 
Mathews, J. A., and H. Tan. 2009. Biofuels and indirect land use change effects: the debate continues. Biofuels Bioproducts \& BiorefiningBiofpr 3:305-317.

McBroom, M. W., R. S. Beasley, M. T. Chang, and G. G. Ice. 2008a. Water quality effects of clearcut harvesting and forest fertilization with best management practices. Journal of Environmental Quality 37:114-124.

McBroom, M. W., R. S. Beasley, M. T. Chang, and G. G. Ice. $2008 b$. Storm runoff and sediment losses from forest clearcutting and stand reestablishment with best management practices in East Texas, USA. Hydrological Processes 22:1509-1522.

Millennium Ecosystem Assessment. 2005. Ecosystems and human well-being: synthesis. Island Press, Washington, D.C., USA .

National Research Council (NRC). 2008. Water implications of biofuels production in the United States. National Research Council, National Academy of Sciences Press, Washington, D.C., USA.

National Research Council (NRC). 2009. Liquid transportation fuels from coal and biomass. National Research Council, National Academies Press, Washington, D.C., USA.

National Research Council (NRC). 2010. Toward sustainable agricultural systems in the 21 st century. National Research Council, National Academy of Sciences Press, Washington, D.C., USA.

Nelson, R. G., J. C. Ascough, and M. R. Langemeier. 2006. Environmental and economic analysis of switchgrass production for water quality improvement in northeast Kansas. Journal of Environmental Management 79:336-347.

Pate, R., M. Hightower, C. Cameron, and W. Einfeld. 2007. Overview of energy-water interdependencies and the emerging energy demands on water resources. Report SAND 2007-1349C. Sandia National Laboratories, Albuquerque, New Mexico, USA.

Ramseur, J. L. 2010. Oil spills in U.S. coastal waters: background, governance and issue for congress. Congressional Research Service 7-5700, Washington D.C., USA.
Rasse, D. P., J. T. Ritchie, W. R. Peterson, J. Wei, and A. J. M. Smucker. 2000. Rye cover crop and nitrogen fertilization effects on nitrate leaching in inbred maize fields. Journal of Environmental Quality 29:298-304.

Robertson, G. P., L. W. Burger, C. L. Kling, R. Lowrance, and D. J. Mulla. 2007. New approaches to environmental management research at landscape and watershed scales. Pages 27-50 in M. Schnepf and C. Cox, editors. Managing agricultural landscapes for environmental quality. Soil and Water Conservation Society, Ankeny, Iowa, USA.

Robertson, G. P., V. H. Dale, O. C. Doering, S. P. Hamburg, J. M. Melillo, M. M. Wander, W. J. Parton, P. R. Adler, J. N. Barney, R. M. Cruse, C. S. Duke, P. M. Fearnside, R. F. Follett, H. K. Gibbs, J. Goldemberg, D. J. Mladenoff, D. Ojima, M. W. Palmer, A. Sharpley, L. Wallace, K. C. Weathers, J. A. Wiens, and W. W. Wilhelm. 2008. Agriculture - sustainable biofuels redux. Science 322:49-50.

Robertson, G. P., S. K. Hamilton, W. J. Parton, and S. J. Del Grosso. 2011. The biogeochemistry of bioenergy landscapes: carbon, nitrogen, and water considerations. Ecological Applications, in press.

Rowe, R. L., N. R. Street, and G. Taylor. 2009. Identifying potential environmental impacts of large-scale deployment of dedicated bioenergy crops in the UK. Renewable \& Sustainable Energy Reviews 13:260-279.

Terrell, C. R., and P. B. Perfettie. 1993. Water quality indicators guide: surface waters. U.S. Department of Agriculture Soil Conservation Service. Washington, D.C., USA.

Steiner, J. L., P. J. Starks, J. A. Daniel, J. D. Garbrecht, D. Moriasi, S. McIntyre, and J. S. Chen. 2008. Environmental effects of agricultural conservation: a framework for research in two watersheds in Oklahoma's Upper Washita River Basin. Journal of Soil and Water Conservation 63:443-452.

Swinton, S. M., F. Lupi, G. P. Robertson, and S. K. Hamilton. 2007. Ecosystem services and agriculture: cultivating agricultural ecosystems for diverse benefits. Ecological Economics 64:245-252. 
Vadas, P. A., K. H. Barnett, and D. J. Undersander. 2008. Economics and energy of ethanol production from alfalfa, corn, and switchgrass in the Upper Midwest, Bioenergy Research 1:44-55.

Wiebe, K., and N. Gollehon, editors. 2006. Agricultural resources and environmental indicators. Economic Information Bulletin No. 16. U.S. Department of Agriculture, Washington, D.C., USA.

Wu, M., M. Mintz, M. Wang, and S. Arora. 2009.

Water consumption in the production of ethanol and petroleum gasoline. Environmental Management 44:981-997. 